\title{
СУИЦИДАИЬНОЕ ПОВЕДЕНИЕ У ДЕТЕЙ И ПОДРОСТКОВ КОРЕННЫХ НАРОДОВ СИБИРИ: КАИНИЧЕСКИЕ ФАКТОРЫ РИСКА
}

\author{
Н.Б. Семёнова
}

ФГБНУ «Федеральный исследовательский центр «Красноярский научный центр Сибирского отделения Российской академии наук", НИИ медицинских проблем Севера, г. Красноярск, Россия

Контактная информация:

Семёнова Надежда Борисовна - доктор медицинских наук (SPIN-код: 8340-6208; ORCID iD: 0000-00022790-7740; Researcher ID: U-4748-2017). Место работы и должность: главный научный сотрудник ФГБНУ "Федеральный исследовательский центр “Красноярский научный центр Сибирского отделения Российской академии наук", НИИ медицинских проблем Севера. Адрес: 660036, г. Красноярск, Академгородок, д. 50. Телефон: (913) 539-86-02, эмектронный адрес: snb237@gmail.com

Показатели смертности от самоубийств среди детей и подростков коренных народов Сибири во много раз превышают средние значения по Российской Федерации, что требует тщательного анализа данного социального явления и объяснения его причин. Цель исследования: изучить распространённость психических нарушений у детей и подростков коренных популяций Сибири - якутов, эвенов, эвенков, алтайцев, агинских бурят и тувинцев с использованием международно принятых стандартизированных методов и подходов. Объект и методы исследования. Обследованы дети и подростки в возрасте 7-15 лет, учащиеся общеобразовательных школ, проживающие в сельской местности в четырех национальных субъектах РФ: Республике Саха (Якутия), Республике Алтай, Агинском Бурятском округе и Республике Тыва. Обследование проходило в два этапа. На первом этапе проведен скрининг психического здоровья у 5208 детей и подростков (1662 якуты, эвены и эвенки, 1044 алтайцы, 1797 буряты, 705 тувинцы) с использованием опросника М. Раттера для учителей (RTQ, шкала В). На втором этапе проведена более детальная психиатрическая оценка детей, получивших отрицательный результат по шкале RTQ. Результаты. Распространённость психических расстройств среди якутов, эвенов и эвенков составила $16,3 \%$, среди алтайцев - 12,1\%, агинских бурят - 7,4\%, тувинцев - 29,2\%. У мальчиков нарушения встречаются в 2-3 раза чаще, чем у девочек. В структуре психических нарушений на первое место выходят нарушения поведения, на второе - гиперкинетические расстройства, на третье - эмоциональные расстройства. Более $45 \%$ детей и подростков с психическими расстройствами имеют сочетанные формы нарушений. Выводы. Полученные данные указывают на то, что существует необходимость в мерах медицинского вмешательства, направленных на оказание эффективной помощи детям и подросткам с проблемами психического здоровья.

Ключевые слова: подростки, дети, суицид, коренные народы, Сибирь, факторы риска, психическое здоровье, эпидемиология

Мы продолжаем цикл научных публикаций, посвящённых факторам риска суицидального поведения у детей и подростков коренных народов Сибири - якутов, эвенов и эвенков, алтайцев, бурят, тувинцев. В представленном материале будут рассмотрены клинические факторы риска.

Клинические факторы являются второй, наиболее часто упоминаемой причиной, ассоциированной с суицидальным поведением. Недавние исследования, проведённые K.M. Holland и соавт. [1] по изучению обстоятельств смерти у 482 подростков в возрасте от 11 до 15 лет показали, что проблемы, связанные с психическим здоровьем встречаются у 52\% молодых людей, совершивших завершённый суицид. В структуре выявленных расстройств $60 \%$ случаев составляла депрессия, 37,8\% наруше- ний приходились на синдром дефицита внимания и гиперактивности, $12 \%$ - другие психические расстройства (биполярное, обсессивнокомпульсивное, тревожное, шизофрению и другие). Нарушения психического здоровья обычно сопровождались недавним кризисом или стрессовым событием. Злоупотребление алкоголем и / или психоактивными веществами имели место в 8\% случаев. В 27,6\% случаев самоубийства были совершены в импульсивном состоянии и характеризовались немедленным, незапланированным ответом на острый конфликт или негативную ситуацию. Однако дефицит импульсного контроля авторы расценили как индикатор других психических нарушений, таких как расстройство поведения или эксплозивная психопатия, характеризующиеся вспышками гнева, которые часто не со- 
ответствовали ситуации и были спровоцированы относительно несущественными событиями.

По данным S.J. Cash и соавт. [2] психические расстройства встречаются у 80-90\% подростков, совершивших суицид. Как при завершённом суициде, так и при попытке самоубийства наиболее распространёнными психиатрическими диагнозами являются депрессивное расстройство, биполярное расстройство, расстройство поведения и расстройства, связанные с употреблением алкоголя и наркотиков. Депрессия чаще других психических нарушений приводит к самоубийству: до 60\% жертв суицида среди подростков страдали депрессивным расстройством на момент смерти, от 40 до 80\% соответствовали диагностическим критериям депрессии на момент попытки.

Известно, что изменения в поведении у подростков могут быть внешними проявлениями нормального физиологического развития и обусловлены биологическими факторами [3]. В исследованиях В. Luna и соавт. [4] было показано, что в возрасте 11 лет у девочек и 12 лет у мальчиков активируются процессы созревания головного мозга, в частности, префронтальной коры, происходит дендритная «обрезка» и миелинизация нервных волокон, итогом чего является развитие когнитивного контроля над поведением. Однако активизация созревания головного мозга имеет важное значение не только для когнитивного и аффективного развития подростков, но также является риском нарушений психического здоровья [5]. Внешние проявления эмоциональных проблем у подростков - нустойчивость настроения, эмоциональная лабильность, конфликтность, склонность к эмоциональным переживаниям - могут быть признаками более ширкого спектра изменений поведенческой регуляции, в частности, проявлениями различных форм психопатологии [6, $7,8]$.

В социальном плане возраст 11-15 лет связан с изменениями в общественной жизни, переходом от начального обучения к средней и высшей школе, расширением межличностных коммуникаций, установлением новой системы отношений, что часто сопровождается повышенными стрессами. Обстоятельства, предшествующие самоубийству у молодежи, обычно включают взаимодействие множества индивидуальных, социальных, семейных и школьных проблем, которые кумулируют и увеличивают риск суицида. Однако именно психические нарушения являются причиной появления суицидальных мыслей и приводят к развитию и прогрессированию суицидального поведения [1]. Показано, что основным предиктором суицидальных мыслей у детей и подростков является депрессия $[9,10]$. Также установлена связь депрессии, возникшей впервые в возрасте 11-15 лет, с риском совершения суицида или суицидальной попытки во взрослом возрасте $[11,12$, 13].

Подтверждена высокая роль эмоционального неблагополучия в формировании суицидального поведения у коренных народов. Так, при изучении уровня оптимизма и надежды у американских индейцев и коренных жителей Аляски [14], показано, что чувство безысходности и отсутствие оптимизма приводят к возникновению мыслей о самоубийстве. Исследования, проведённые в штате Монтана [15] среди молодежи двух групп (коренных американцев и белых), показали, что единственным статистически значимым предиктором суицидальных мыслей или попыток является чувство печали и безысходности. При изучении причин самоубийства среди коренных подростков Австралии (штат Квинсленд) [16] одной из основных причин суицида авторы назвали психические расстройства, в частности, СДВГ.

Исследования, проведённые в Сибирском регионе, выявили высокую распространённость психических нарушений у подростков, совершивших суицид или суицидальную попытку. Так, отклонения со стороны психического здоровья отмечались у 84,7\% человек, совершивших суицидальную попытку в Иркутской области $[17,18]:$ у 67,4\% подростков отмечались кратковременные и преходящие аффективно насыщенные реакции на личностно значимые психогении, у 8,7\% - расстройства поведения, у 4,3\% - шизофрения, у 4,3\% - депрессивное расстройство. Состояние алкогольного опьянения в момент совершения суицидальной попытки зафиксировано у 30,4\% молодых людей. Среди подростков, совершивших завершённый суицид, большинство молодых людей (75\%) ранее не попадали в поле зрения психиатров. В структуре психических расстройств, зарегистрированных на момент совершения суицида, у 19,2\% выявлена умственная отсталость, у $7,2 \%$ - шизофрения и органическое расстройство в связи с эпилепсией. В состоянии алкогольного опьянения находились $27,1 \%$ моло- 
дых людей $[18,19]$. Клиническое обследование подростков после совершения суицида, проведённое в Забайкальском крае [20, 21], выявило наличие пограничной психической патологии с нарушениями волевых и аффективных процессов. Наиболее часто диагностировались расстройство адаптации (55-81\%), расстройство поведения, специфическое для детского возраста $(9-14 \%)$, расстройство личности $(11 \%)$ и депрессивный эпизод (6\%).

Таким образом, клинические факторы риска вносят существенный вклад в формирование суицидального поведения, что объясняет высокую актуальность изучения распространённости нарушений психического здоровья у детей и подростков коренных популяций Сибири. Однако эпидемиологические исследования в Сибирском регионе ранее не проводились.

Целью настоящего исследования явилось изучение распространённости психических нарушений у детей и подростков коренного населения Сибири с использованием международно принятых стандартизированных методов и подходов.

\section{Задачи исследования:}

1. Изучить распространённость и структуру психических расстройств у детей и подростков коренных популяций Сибири - якутов, эвенов, эвенков, алтайцев, бурят и тувинцев.

2. Выявить частоту сочетанных нарушений у детей и подростков, имеющих психические расстройства.

3. Провести сравнительный анализ частоты и структуры психических нарушений у разных представителей коренных популяций Сибири и сравнить их с показателями детей и подростков других стран.

Материалы и методы.

Участники и процедура проведения исследования

Исследование проводилось в четырех национальных субъектах РФ: Республике Саха (Якутия) (РС(Я)), Республике Алтай (РА), Агинском Бурятском округе (АБО) и Республике Тыва (РТ). Для проведения исследования отобраны населенные пункты с наиболее компактным проживанием коренного населения. Большинство представителей коренных популяций проживают в сельской местности, поэтому обследование проводилось в поселках, расположенных в национальных субъектах РФ. В Якутии отобрано 13 поселков: пос. Депутатский, сёла Казачье, Усть-Куйга, Усть-Янск,
Сайылык (Усть-Янский улус, расположенный в Арктических районах); сёла Абага, Петропавловск, Эжанцы, Кюпцы (Амгинский и УстьМайский улусы, расположенные в центральных и восточных районах); сёла Дабан, Тяня, Кыллах, Токко (Олекминский улус, южные районы). В Республике Алтай отобрано 6 населенных пунктов: пос. Улаган, сёла Акташ и Чибит (Улаганский район), пос. Кош-Агач, сёла Бельтир и Мухор-Тархата (Кош-Агачский районе), пос. Майма (Майминский район). В Агинском Бурятском округе отобрано 2 поселка в сельской местности: пос. Агинское (Агинский район) и Могойтуй (Могойтуйский район). В Тыве отобрано 5 поселков (кожуунов) в западных районах сельской местности: ЧааХоль (Чаа-Хольский кожуун), Тээли (Бэйайгинский кожуун), Чадан (Дзун-Хемчикский кожуун), Хандагайты (Овюрский Кожуун) и Торгалыг (Улуг-Хемский кожуун).

В исследование включены дети и подростки коренного населения (якуты, эвены, эвенки, алтайцы, агинские буряты и тувинцы), учащиеся общеобразовательных школ. Из исследования исключены дети, имевшие неврологический или психиатрический диагноз, такой как шизофрения, эпилепсия или умственная отсталость, который ранее уже был зарегистрирован в статистической отчетности.

В соответствии с принятым международным подходом к проведению кросс-культурных эпидемиологических исследований в психиатрии (Goodman R., Scott S., 1997), обследование проходило в два этапа. На первом этапе у всех участников оценивалось поведение с использованием опросника Раттера для учителей (Rutter, 1967, Rutter, Tizard, \& Whitmore, 1970). Цели и процедура проведения исследования были разъяснены преподавателям и административному персоналу школ, принимавшим участие в исследовании.

Всего было получено 5208 анкет (97\% от общей выборки), в которых содержалась информация о внешнем и внутреннем поведении учащихся. В Якутии получено 1662 анкеты, из них 881 (53,0\%) включали данные о мальчиках и $781(46,9 \%)$ о девочках; 616 (37,1\%) анкет включали данные о детях в возрасте 7-10 лет и 1046 (62,9\%) в возрасте 11-15 лет. В Республике Алтай получено 1044 анкеты, из них 501 $(47,9 \%)$ содержали информацию о мальчиках и $543(52,1 \%)$ о девочках; 473 (45,3\%) анкеты содержали информацию о детях 7-10 лет и 571 
(54,7\%) о подростках 11-15 лет. В Агинском Бурятском округе получено 1797 анкет, из которых 938 (52,2\%) включали информацию о мальчиках и 859 (47,8\%) о девочках; 1083 $(60,3 \%)$ анкет включали данные о детях в возрасте 7-10 лет и $714(39,7 \%)$ в возрасте $11-15$ лет. В Республике Тыва получено 705 анкет, из них $382(54,2 \%)$ содержали информацию о мальчиках и 323 (45,8\%) о девочках; 464 $(65,8 \%)$ анкеты содержали информацию о детях и $241(34,2 \%)$ о подростках.

На втором этапе проведен психиатрический осмотр всех «скрин - положительных» испытуемых с постановкой диагнозов и $20 \%$ случайно выбранных «скрин - отрицательных» испытуемых.

\section{Методика}

Опросник Раттера для учителей (RTQ, Scale B) является стандартизированным скрининговым тестом, оценивающим наличие психических проблем у детей и подростков. RTQ разработан в 60-е гг. и впервые применялся при проведении эпидемиологических исследований на острове Уайт, затем подвергался пересмотру (Rutter, 1967; Rutter, Tizard, and Whitmore, 1970). Русская версия опросника была использована в предыдущих исследованиях психического здоровья и адаптации детей [22, 23, 24].

Опросник предназначен для детей 7-16 лет, состоит из 26 коротких высказываний, касающихся поведения ребенка, которые учитель отмечает как «0» - несоответствующие определённому ребенку, «1»- отчасти соответствующие или «3»- полностью соответствующие. Общая оценка может колебаться от 0 до 52 баллов. Согласно авторской методике, сначала вычисляют общую оценку. Далее детей, у которых общая оценка равна 9 баллов и более, выделяют в группу риска. Затем вычисляют оценки эмоциональных расстройств (сумма пп. 7. "Часто беспокоится и волнуется по разным поводам", 10. "Часто кажется жалким, несчастным, плачущим и страдающим", 17. "Похоже, что боится новых вещей или новых ситуаций” и 23. "Плакал по пути в школу или отказывался заходить в здание школы в течение последнего года") и отклонений в поведении (сумма пп. 4. "Часто ломает или портит свои или чужие вещи", 5. "Часто дерётся или слишком задирает других детей”, 15. "Часто непослушен”, 19. “Часто говорит неправду”, 20. "Воровал вещи один раз или чаще в течение последнего года" и 26. “Обижает других детей”). Кроме того, оценивается гиперактивность: сумма пп. 1. “Очень непоседлив, ему трудно усидеть на одном месте долгое время", 2. "Вертится и суетится" и 16. "Не может заниматься чем-нибудь более нескольких минут".

Психиатрическая диагностика

На втором этапе исследования специалист по психическому здоровью провел полуструктурированное психиатрическое интервью с детьми. При проведении интервьюирования присутствовали медицинские сотрудники из числа коренного сообщества - психиатр, педиатр или школьная медсестра, которые помогали вести беседу с детьми и подростками.

Данные об эмоциональном состоянии и поведении детей были дополнены сведениями из медицинской документации и отчётов от учителей. Полученная информация о психическом состоянии ребенка была обобщена и проанализирована, после чего вынесено решение о наличии и типе психического расстройства, если таковое имеется, в соответствии с МКБ-10 (Всемирная организация здравоохранения, 1994).

\section{Статистический анализ}

Статистическая обработка полученных результатов проводилась с использованием пакета прикладных программ STATISTICA for Window, Version X. Для анализа вида распределения количественных данных мы применяли критерий Шапиро-Уилка.

Статистический анализ бинарных признаков проводился с подсчетом относительной частоты (\%) и 95\% ДИ. Сравнение групп по качественному бинарному признаку проводилось с помощью $\chi^{2}$ и точного критерия Фишера. Величина уровня значимости различий принималась при $\mathrm{p}=0,05$, то есть при ошибке 5\%.

Результаты исследования .

Доля детей и подростков, у которых показатель общих нарушений по опроснику RTQ превысил 9 баллов и более, среди якутов, эвенов и эвенков составила $16,3 \%$, среди алтайцев $12,1 \%$, среди агинских бурят $7,4 \%$, среди тувинцев 29,2\% (рис. 1).

Самая высокая распространённость психических нарушений регистрируется в Тыве $(29,2 \%)$, где общий показатель значительно превышает значения, полученные у детей и подростков в Якутии $(16,3 \%$; $=0,004)$, на Алтае $(12,1 \% ; \mathrm{p}<0,001)$ и в Агинском Бурятском округе $(7,4 \% ; \mathrm{p}<0,001)$. 


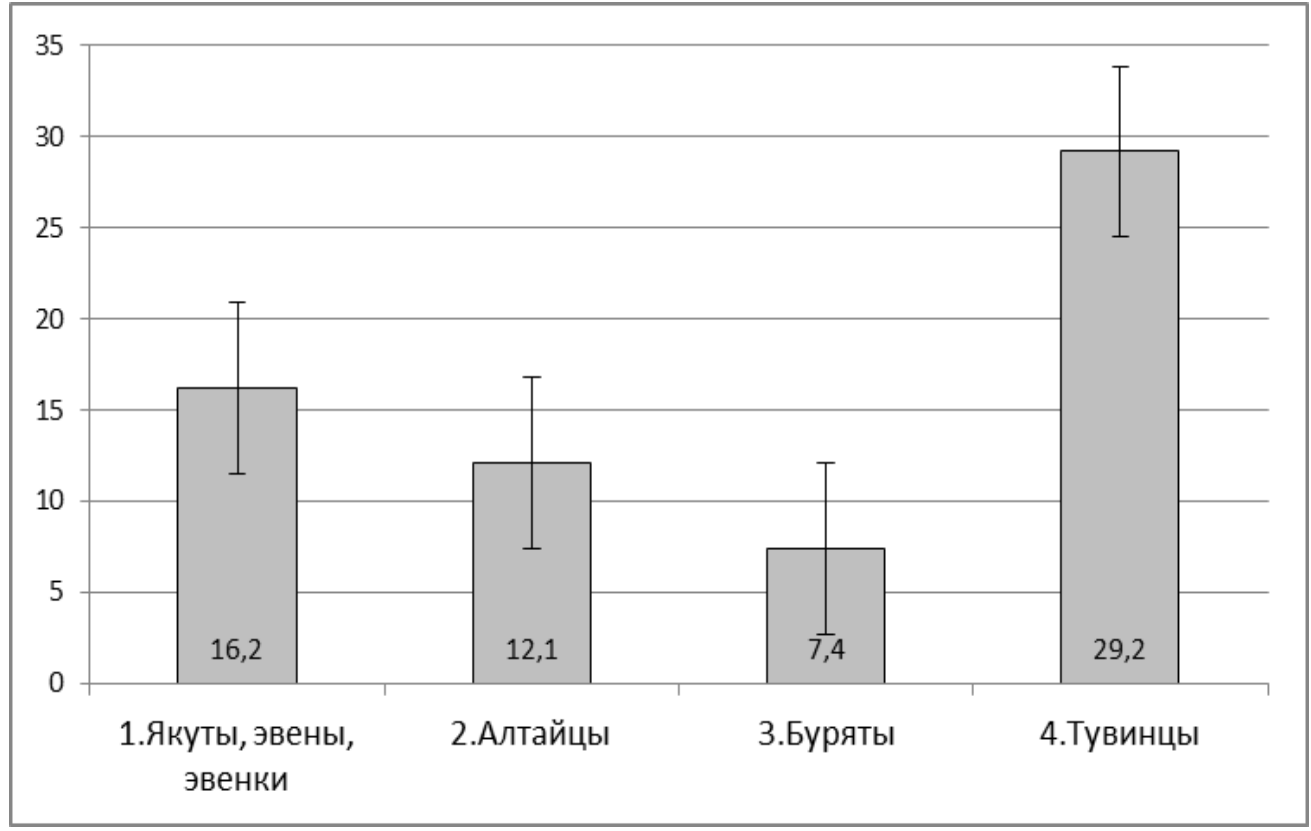

Примечание: $\mathrm{p}_{1-4}=0,004 ; \mathrm{p}_{2-4}<0,001 ; \mathrm{p}_{3-4}<0,001 ; \mathrm{p}_{1-2}=0,002 ; \mathrm{p}_{1-3}<0,001 ; \mathrm{p}_{2-3}<0,001$

Puc. 1. Частота психических нарушений у детей и подростков (\%).

На второе место по частоте нарушений выходит Республика Саха (Якутия), показатели которой превышают значения на Алтае $(\mathrm{p}=0,002)$ и в Агинском Бурятском округе $(\mathrm{p}<0,001)$.На третье место выходит Республика Алтай, показатели которой выше, чем в Агинском Бурятском округе $(\mathrm{p}<0,001)$. Самая низкая распространённость психических нарушений регистрируется в Агинском Бурятском округе $(7,4 \%)$, где общий показатель патологии ниже, чем в Якутии $(\mathrm{p}<0,001)$, на Алтае $(\mathrm{p}<0,001)$ и в Тыве $(\mathrm{p}<0,001)$.

Показатели распространённости психических нарушений, стандартизированные по полу и возрасту, представлены в табл. 1.

Во всех анализируемых группах у мальчиков нарушения встречаются чаще, по сравнению с девочками: среди якутов, эвенов и эвенков в 2,8 раза, среди алтайцев в 3 раза, среди агинских бурят в 3,1 раза, среди тувинцев в 2,1 раза. Гендерные различия ещё более выражены для расстройств поведения: у якутов, эвенов и эвенков в 3,5 раза, у алтайцев в 3,6 раза, у агинских бурят в 3,7 ра3, у тувинцев в 2,7 раз.

У мальчиков, проживающих в Тыве, распространённость нарушений выше, по сравнению с мальчиками, проживающими в $\mathrm{PC}(Я)$ в 1,6 раза $(\mathrm{p}<0,05)$, в РА в 2,1 раз $(\mathrm{p}<0,001)$, в АБО в 3,5 раз $(\mathrm{p}<0,001)$. Ещё больше эта разница выражена у девочек. У девочек, прожи- вающих в Тыве, распространённость нарушений выше, по сравнению с девочками, проживающими в $\operatorname{PC}(Я) 2,3$ раза $(\mathrm{p}<0,001)$, в РА в 3,1 раз $(\mathrm{p}<0,001)$, в АБО в 5,4 раза $(\mathrm{p}<0,001)$.

Расстройства поведения преобладают над эмоциональными расстройствами во всех анализируемых группах. Среди детей и подростков, проживающих в Якутии, нарушения поведения превышают уровень эмоциональных расстройств в 2,8 раза $(12,0 \%$ и $4,3 \%)$, на Алтае - в 2,9 раза $(9,0 \%$ и $3,1 \%)$, в АБО - в 2,5 раза $(5,3 \%$ и $2,1 \%)$, в Тыве - в 2,5 раза $(18,1 \%$ и $7,1 \%)$.

Распространённость отдельных психических расстройств

Три категории психических расстройств подвергались психиатрической оценке: эмоциональные расстройства, нарушения поведения и гиперкинетические расстройства. Распространённость специфических психических расстройств, вошедших в эти три рубрики в соответствии с критериями МКБ-10, представлена в табл. 2.

Структура выявленных нарушений у представителей разных коренных популяций оказалась примерно одинаковой. Наиболее частыми психиатрическими диагнозами были нарушения поведения: в РС(Я) $-2 \%$, в РА - $9 \%$, в АБО $-5,3 \%$, в РТ $-21 \%$. На второе место выходили гиперкинетические расстройства: в $\mathrm{PC}(Я)-$ $6,5 \%$, в РА $-5,5 \%$, в АБО $-3,1 \%$, в РТ $-11,4 \%$. 
Показатели распространенности нарушений поведения и эмоциональных расстройств,

Таблиияа 1 стандартизированные по полу и возрасту (\%, 95\% ДИ)

\begin{tabular}{|c|c|c|c|c|}
\hline \multirow{2}{*}{ Группы детей } & \multirow[b]{2}{*}{$\mathrm{n}$} & \multicolumn{3}{|c|}{ Распространённость } \\
\hline & & Общие проблемы & $\begin{array}{c}\text { Расстройства } \\
\text { поведения }\end{array}$ & $\begin{array}{c}\text { Эмоциональные } \\
\text { расстройства }\end{array}$ \\
\hline Якутыл, эвеньл, эвенки & 1662 & $16,3(14,6-18,2)$ & $12,0(10,5-13,7)$ & $4,3(3,4-5,3)$ \\
\hline Мальчики & 881 & $23,4 *(20,7-26,3)$ & $18,0 *(15,6-20,7)$ & $5,3 *(4,0-7,0)$ \\
\hline Девочки & 781 & $8,3 *(6,6-10,5)$ & $5,2 *(3,9-7,0)$ & $3,0 *(2,0-4,5)$ \\
\hline Дети 7-10 лет & 616 & $16,4(13,7-19,5)$ & $12,2(9,8-14,9)$ & $4,2(2,9-6,1)$ \\
\hline Мальчики & 339 & $23,5^{*}(19,4-28,4)$ & $18,3^{*}(14,5-22,8)$ & $5,3(3,4-8,2)$ \\
\hline Девочки & 277 & $7,6^{*}(5,0-11,3)$ & $4,7 *(2,8-7,9)$ & $2,9(1,5-5,6)$ \\
\hline Подростки 11-15 лет & 1046 & $16,3(14,1-18,6)$ & $11,9(10,1-14,1)$ & $4,3(3,2-5,7)$ \\
\hline Мальчики & 542 & $23,2 *(19,9-27,0)$ & $17,9 *(14,9-21,3)$ & $5,3(3,8-7,6)$ \\
\hline Девочки & 504 & $8,7 *(6,6-11,5)$ & $5,5^{*}(3,9-7,9)$ & $3,2(2,0-5,1)$ \\
\hline Алтайцฺы & 1044 & $12,1(10,2-14,2)$ & $9,0(7,4-10,9)$ & $3,1(2,2-4,3)$ \\
\hline Мальчики & 501 & $18,6^{*}(15,4-22,2)$ & $14,4 *(11,6-17,7)$ & $4,2 *(2,8-6,3)$ \\
\hline Девочки & 543 & $6,1 *(4,4-8,4)$ & $4,0 *(2,7-6,1)$ & $2,0 *(1,1-3,6)$ \\
\hline Дети 7-10 лет & 473 & $7,8(5,7-10,6)$ & $6,6(4,6-9,1)$ & $1,3(0,6-2,7)$ \\
\hline Мальчики & 233 & $12,0 *(8,5-16,8)$ & $10,7 *(7,4-15,4)$ & $1,3(0,5-3,7)$ \\
\hline Девочки & 240 & $3,7 *(2,0-7,0)$ & $2,5^{*}(1,2-5,3)$ & $1,2(0,4-3,6)$ \\
\hline Подростки 11-15 лет & 571 & $15,6(12,8-18,8)$ & $11,0(8,7-13,8)$ & $4,5(3,1-6,5)$ \\
\hline Мальчики & 268 & $24,2 *(19,5-29,7)$ & $17,5^{*}(13,5-22,5)$ & $6,7 *(4,3-10,4)$ \\
\hline Девочки & 303 & $7,9 *(5,4-11,5)$ & $5,3 *(3,3-8,4)$ & $2,6 *(1,4-5,1)$ \\
\hline Агинские буряты & 1797 & $7,4(6,3-8,7)$ & $5,3(4,4-6,5)$ & $2,1(1,5-2,8)$ \\
\hline Мальчики & 938 & $11,0 *(9,1-13,1)$ & $8,2 *(6,6-10,1)$ & $2,8(1,9-4,0)$ \\
\hline Девочки & 859 & $3,5^{*}(2,5-4,9)$ & $2,2 *(1,4-3,4)$ & $1,4(0,8-2,4)$ \\
\hline Дети 7-10 лет & 1083 & $8,4(6,9-10,2)$ & $6,2(4,9-7,8)$ & $2,2(1,5-3,3)$ \\
\hline Мальчики & 559 & $13,1 *(10,5-16,1)$ & $10,0 *(7,8-12,8)$ & $3,0(1,9-4,8)$ \\
\hline Девочки & 524 & $3,4 *(2,2-5,4)$ & $2,1 *(1,2-3,7)$ & $1,3(0,7-2,6)$ \\
\hline Подростки 11-15 лет & 714 & $5,9(4,4-7,8)$ & $4,1(2,8-5,8)$ & $1,8(1,1-3,1)$ \\
\hline Мальчики & 379 & $7,9 *(5,6-11,1)$ & $5,5 *(3,7-8,3)$ & $2,4(1,3-4,4)$ \\
\hline Девочки & 335 & $3,6 *(2,1-6,1)$ & $2,4 *(1,2-4,6)$ & $1,2(0,5-3,0)$ \\
\hline Тувинцы & 705 & $29,2(25,2-33,5)$ & $18,1(15,4-21,2)$ & $7,1(5,5-9,0)$ \\
\hline Мальчики & 382 & $39,0 *(32,4-46,0)$ & $26,2 *(21,0-32,1)$ & $7,3(5,5-9,9)$ \\
\hline Девочки & 323 & $18,9 *(14,7-24,0)$ & $9,6^{*}(7,7-12,0)$ & $6,8(4,6-10,0)$ \\
\hline Дети 9-10 лет & 464 & $28,5(24,0-33,5)$ & $17,6(14,5-21,2)$ & $7,9(6,1-10,4)$ \\
\hline Мальчики & 250 & $38,4 *(31,7-45,6)$ & $25,6 *(19,8-32,4)$ & $8,4(6,2-11,1)$ \\
\hline Девочки & 214 & $18,2 *(13,4-24,3)$ & $9,3 *(7,2-12,0)$ & $7,5(4,7-11,1)$ \\
\hline Подростки 14-15 лет & 241 & $30,5(22,3-40,3)$ & $19,0(13,4-26,2)$ & $5,4(3,3-8,8)$ \\
\hline Мальчики & 132 & $40,2(26,9-55,1)$ & $27,3 *(17,9-39,2)$ & $5,3(2,7-10,1)$ \\
\hline Девочки & 109 & $20,2(12,7-30,5)$ & $10,1 *(6,5-15,4)$ & $5,5(2,6-11,4)$ \\
\hline
\end{tabular}

Примечание: * мальчики > чем девочки $(\mathrm{p}<0,05)$

На третье место - эмоциональные расстройства: в $\mathrm{PC}(Я)-4,3 \%$, в $\mathrm{PA}-3,1 \%$, в АБО $-2,1 \%$, в РТ $-8,7 \%$. Распространённость социализированных расстройств поведения была в три раза выше, по сравнению с несоциализированными: в РС (Я) $-9,1 \%$ и $2,8 \%$, в $\mathrm{PA}-7,6 \%$ и $1,4 \%$, в АБО - 4,2\% и $1,2 \%$, в РТ $-17,2 \%$ и $4,4 \%$ соответственно. Тревожные расстройства встречались чаще, чем депрессивные: в РС(Я)$3,2 \%$ и $1,7 \%$, в АБО $-2,1 \%$ и $1,0 \%$, в $\mathrm{PТ}-7,7 \%$ и 2,3\% соответственно; за исключением РА, где тревожные расстройства составили - $1,8 \%$, а депрессивные - 2,2\%. Депрессивные расстройства выявлены у 1,7\% детей, проживающих в Якутии, у 2,2\% детей, проживающих в РА, у $1,0 \%$ детей в АБО и у $2,3 \%$ детей в РТ. Около $40 \%$ детей и подростков с психическими расстройствами имели более одного диагноза: в РС (Я) $-40,6 \%$, в РА $-53,2 \%$, в АБО $-45,9 \%$, в РТ $-40 \%$ (рис. 2). 
Отдельные психические расстройства у детей и подростков коренных популяций Сибири, стандартизированные по полу и возрасту (\%, 95\% ДИ)

\begin{tabular}{|c|c|c|c|c|c|c|c|c|c|}
\hline \multirow{2}{*}{ Показатель } & \multicolumn{3}{|c|}{ Дети 7-10 лет } & \multicolumn{3}{|c|}{ Подростки 11-15 лет } & \multicolumn{3}{|c|}{ Все дети } \\
\hline & Мал. & Дев. & Оба пола & Мал. & Дев. & Оба пола & Мал. & Дев. & Оба пола \\
\hline \multicolumn{10}{|l|}{ Якутьл } \\
\hline \multirow{2}{*}{ Эмоциональные расстройства } & 5,3 & 2,9 & 4,2 & 5,3 & 3,2 & 4,3 & 5,3 & 3,0 & 4,3 \\
\hline & $(3,4-8,2)$ & $(1,5-5,6)$ & $(2,9-6,1)$ & $(3,8-7,6)$ & $(2,0-5,1)$ & $(3,2-5,7)$ & $(4,0-7,0)$ & $(2,0-4,5)$ & $(3,4-5,3)$ \\
\hline \multirow{2}{*}{ Тревожные расстройства } & 3,5 & 1,8 & 2,8 & 5,0 & 1,8 & 3,4 & 4,4 & 1,8 & 3,2 \\
\hline & $(2,0-6,1)$ & $(0,8-4,1)$ & $(1,7-4,4)$ & $(3,4-7,1)$ & $(0,9-3,3)$ & $(2,5-4,7)$ & $(3,2-6,0)$ & $(1,1-3,0)$ & $(2,4-4,1)$ \\
\hline \multirow[t]{2}{*}{ Депрессия } & 2,1 & 0,7 & 1,5 & 2,6 & 1,2 & 1,9 & 2,4 & 1,0 & 1,7 \\
\hline & $(1,0-4,2)$ & $(0,2-2,6)$ & $(0,8-2,7)$ & $(1,5-4,3)$ & $(0,5-2,6)$ & $(1,2-2,9)$ & $(1,6-3,6)$ & $(0,5-2,0)$ & $(1,2-2,5)$ \\
\hline \multirow[t]{2}{*}{ Расстройства поведения } & $18,3^{*}$ & $4,7^{*}$ & 12,2 & $17,9 *$ & $5,5^{*}$ & 11,9 & $18,0^{*}$ & $5,2 *$ & 12,0 \\
\hline & $|(14,5-22,8)|$ & $(2,8-7,9)$ & $(9,8-14,9)$ & $\mid(14,9-21,3)$ & $(3,9-7,9)$ & $(10,1-14,1)$ & $(15,6-20,7)$ & $(3,9-7,0)$ & $(10,5-13,7)$ \\
\hline \multirow[t]{2}{*}{ Несоциализированные } & 5,9 & 1,1 & 3,7 & 3,3 & 1,2 & 2,3 & $4,3 *$ & $1,1 *$ & 2,8 \\
\hline & $(3,9-8,9)$ & $(0,4-3,1)$ & $(2,5-5,5)$ & $(2,1-5,2)$ & $(0,5-2,6)$ & $(1,5-3,4)$ & $(3,2-5,9)$ & $(0,6-2,2)$ & $(2,1-3,7)$ \\
\hline \multirow[t]{2}{*}{ Социализированные } & $12,4 *$ & $3,6^{*}$ & 8,4 & $14,4^{*}$ & $4,4 *$ & 9,6 & $13,6^{*}$ & $4,1 *$ & 9,1 \\
\hline & $(9,3-16,3)$ & $(2,0-6,5)$ & $(6,5-10,9)$ & $(11,7-17,6)$ & $(2,9-6,5)$ & $(7,9-11,5)$ & $(11,5-16,0)$ & $(2,9-5,7)$ & $(7,8-10,6)$ \\
\hline \multirow{2}{*}{$\begin{array}{l}\text { Гиперкинетические } \\
\text { расстройства }\end{array}$} & $13,0^{*}$ & $2,5^{*}$ & 8,2 & $9,0 *$ & $1,6^{*}$ & 5,4 & $10,5^{*}$ & $1,9 *$ & 6,5 \\
\hline & $(9,8-17,0)$ & $(1,2-5,1)$ & $(6,3-10,7)$ & $(6,9-11,7)$ & $(0,8-3,1)$ & $(4,2-6,9)$ & $(8,7-12,8)$ & $(1,2-3,1)$ & $(5,4-7,8)$ \\
\hline \multicolumn{10}{|l|}{ Алтаййы } \\
\hline Эмоциональные расстройства & 1,3 & 1,2 & 1,3 & 6,7 & 2,6 & 4,5 & 4,2 & 2,0 & 3,1 \\
\hline & $(0,5-3,7)$ & $(0,4-3,6)$ & $(0,6-2,7)$ & $(4,3-10,4)$ & $(1,4-5,1)$ & $(3,1-6,5)$ & $(2,8-6,3)$ & $(1,1-3,6)$ & $(2,2-4,3)$ \\
\hline Тревожные расстройства & 0,4 & 0,8 & 0,6 & 3,4 & 2,3 & 2,8 & 2,0 & 1,6 & 1,8 \\
\hline & $(0,1-2,3)$ & $(0,2-3,0)$ & $(0,2-1,8)$ & $(1,8-6,3)$ & $(1,1-4,7)$ & $(1,7-4,5)$ & $(1,1-3,6)$ & $(0,9-3,1)$ & $(1,1-2,8)$ \\
\hline Депрессивные & 0,4 & 0,4 & 0,6 & 4,8 & 2,6 & 3,7 & 2,8 & 1,6 & 2,2 \\
\hline & $(0,1-2,3)$ & $(0,1-2,3)$ & $(0,2-1,8)$ & $(2,9-8,1)$ & $(1,4-5,1)$ & $(2,4-5,5)$ & $(1,7-4,6)$ & $(0,9-3,1)$ & $(1,4-3,2)$ \\
\hline Расстройства поведения & $10,7 *$ & $2,5^{*}$ & 6,6 & $17,5 *$ & $5,3^{*}$ & 11,0 & $14,4 *$ & $4,0 *$ & 9,0 \\
\hline & $(7,4-15,4)$ & $(1,2-5,3)$ & $(4,6-9,1)$ & $(13,5-22,5)$ & $(3,3-8,4)$ & $(8,7-13,8)$ & $(11,6-17,7)$ & $(2,7-6,1)$ & $(7,4-10,9)$ \\
\hline Несоциализированные & 3,0 & - & 1,5 & $2,6^{*}$ & $0,3 *$ & 1,4 & $2,8 *$ & $0,2 *$ & 1,4 \\
\hline & $(1,5-6,1)$ & - & $(0,7-3,0)$ & $(1,3-5,3)$ & $(0,1-1,8)$ & $(0,7-2,7)$ & $(1,7-4,6)$ & $(0,04-1,0)$ & $(0,8-2,3)$ \\
\hline Социализированные & $7,7^{*}$ & $2,5^{*}$ & 5,1 & $14,9 *$ & $4,9 *$ & 9,6 & $11,6^{*}$ & $3,9 *$ & 7,6 \\
\hline & $(4,9-11,9)$ & $(1,2-5,3)$ & $(3,4-7,4)$ & $\mid(11,2-19,7)$ & $(3,0-8,0)$ & $(7,5-12,3)$ & $(9,1-14,7)$ & $(2,5-5,8)$ & $(6,1-9,3)$ \\
\hline Гиперкинетические & $7,3^{*}$ & $1,2 *$ & 4,2 & $10,8 *$ & $3,0 *$ & 6,6 & $9,2 *$ & $2,2 *$ & 5,5 \\
\hline расстройства & $(4,4-11,1)$ & $(0,4-3,6)$ & $(2,8-6,4)$ & $(7,6-15,1)$ & $(1,6-5,5)$ & $(4,9-9,0)$ & $(7,0-12,0)$ & $(1,3-3,8)$ & $(4,3-7,1)$ \\
\hline Агинс & & & & & & & & & \\
\hline Эмоциональные расстройства & 3,0 & 1,3 & 2,2 & 2,4 & 1,2 & 1,8 & 2,8 & 1,4 & 2,1 \\
\hline & $(1,9-4,8)$ & $(0,7-2,6)$ & $(1,5-3,3)$ & $(1,3-4,4)$ & $(0,5-3,0)$ & $(1,1-3,1)$ & $(1,9-4,0)$ & $(0,8-2,4)$ & $(1,5-2,8)$ \\
\hline Тревожные расстройства & 3,6 & 1,3 & 2,5 & 2,4 & 0,9 & 0,9 & 3,1 & 1,2 & 2,1 \\
\hline & $(2,2-5,3)$ & $(0,7-2,7)$ & $(1,7-3,6)$ & $(1,3-4,4)$ & $(0,3-2,6)$ & $(0,4-1,8)$ & $(2,2-4,4)$ & $(0,6-2,1)$ & $(1,5-2,9)$ \\
\hline Депрессивные & 1,8 & 0,6 & 1,2 & 1,3 & 0,3 & 0,8 & 1,6 & 0,5 & 1,0 \\
\hline & $(1,0-3,2)$ & $(0,2-1,7)$ & $(0,7-2,0)$ & $(0,6-3,0)$ & $(0,1-1,6)$ & $(0,3-1,8)$ & $(1,0-2,6)$ & $(0,2-1,2)$ & $(0,6-1,6)$ \\
\hline Расстройства поведения & $10,0 *$ & $2,1 *$ & 6,2 & $5,5^{*}$ & $2,4^{*}$ & 4,1 & $8,2 *$ & $2,2 *$ & 5,3 \\
\hline & $(7,8-12,8)$ & $(1,2-3,7)$ & $(4,9-7,8)$ & $(3,7-8,3)$ & $(1,2-4,6)$ & $(2,8-5,8)$ & $(6,6-10,1)$ & $(1,4-3,4)$ & $(4,4-6,5)$ \\
\hline Несоциализированные & $3,0 *$ & $0,4^{*}$ & 1,7 & 0,3 & 0,3 & 0,3 & 1,9 & 0,3 & 1,2 \\
\hline & $(1,9-4,8)$ & $(0,1-1,4)$ & $(1,1-2,7)$ & $(0,6-1,4)$ & $(0,1-1,6)$ & $(0,1-1,0)$ & $(1,2-3,0)$ & $(0,1-1,0)$ & $(0,7-1,7)$ \\
\hline Социализированные & $7,0^{*}$ & $1,7^{*}$ & 4,4 & $5,3 *$ & $2,1 *$ & 3,8 & $6,3 *$ & $1,9 *$ & 4,2 \\
\hline & $(5,1-9,4)$ & $(0,8-3,1)$ & $(3,3-5,8)$ & $(3,4-8,0)$ & $(1,0-4,2)$ & $(2,6-5,4)$ & $(4,9-8,0)$ & $(1,1-3,0)$ & $(3,3-5,2)$ \\
\hline Гиперкинетич & $6,3 *$ & $1,0 *$ & 3,7 & $3,7 *$ & $0,6^{*}$ & 2,2 & $5,2 *$ & $0,8 *$ & 3,1 \\
\hline расстройства & $(4,5-8,6)$ & $(0,4-2,2)$ & $(2,7-4,9)$ & $(2,2-6,1)$ & $(0,1-1,9)$ & $(0,1-3,6)$ & $(4,0-6,8)$ & $(0,4-1,7)$ & $(2,4-4,0)$ \\
\hline Тувин & & & & & & & & & \\
\hline Эмоциональные расстройства & 10,4 & 7,5 & 9,0 & 9,1 & 7,3 & 8,2 & 9,9 & 7,4 & 8,7 \\
\hline & $(7,5-14,3)$ & $(4,7-11,8)$ & $(6,8-11,7)$ & $(5,4-14,8)$ & $(4,0-12,9)$ & $(5,6-12,0)$ & $(7,5-13,0)$ & $(5,1-10,6)$ & $(7,0-10,9)$ \\
\hline Тревожные расстройства & 9,2 & 6,5 & 7,9 & 9,1 & 5,5 & 7,4 & 9,2 & 6,2 & 7,7 \\
\hline & $(6,4-13$, & $(3,9-10,7)$ & $(5,8-10$ & $(5,4-14,8)$ & $(2,5-11,8$ & $(4,7-11,3)$ & $(6,8-12,2)$ & $(4,0-9,4)$ & $(6,0-9,8)$ \\
\hline Депрессивные & 2,8 & 1,9 & 2,3 & 1,5 & 2,8 & 2,1 & 2,4 & 2,2 & 2,3 \\
\hline & $(1,5-5,2)$ & $(0,6-6,0)$ & $(1,3-4,3)$ & $(0,3-6,8)$ & $(1,2-6,1)$ & $(1,0-4,5)$ & $(1,3-4,3)$ & $(1,0-4,6)$ & $(1,4-3,6)$ \\
\hline Расстройства поведения & $28,8^{*}$ & $10,7 *$ & 19,9 & $34,8^{*}$ & $13,8^{*}$ & 24,7 & $30,9 *$ & $11,8^{*}$ & 21,6 \\
\hline & $(23,2-35,1)$ & $(8,1-14,2)$ & $(16,5-23,9)$ & $(22,7-49,4)$ & $(9,2-20,0)$ & $(17,5-35,5)$ & $(25,0-37,4)$ & $(9,3-14,7)$ & $(18,3-25,1)$ \\
\hline Несоциализированные & $5,6^{*}$ & $0,5^{*}$ & 3,1 & 9,8 & 3,7 & 6,9 & $7,1 *$ & $1,5 *$ & 4,4 \\
\hline & & $(0,1-2,2)$ & $(1,8-5,1)$ & $(5,4-17,1)$ & $(1,7-7,6)$ & $(4,1-11,2)$ & $(4,6-10,8)$ & $(0,8-3,1)$ & $(3,0-6,3)$ \\
\hline Социализированные & $23,2 *$ & $10,3 *$ & 16,9 & $25,0^{*}$ & $10,1 *$ & 17,8 & $23,8^{*}$ & $10,2 *$ & 17,2 \\
\hline & $(18,3-28,9)$ & $(7,5-13,9)$ & $(13,7-20,6)$ & $(16,1-36,6)$ & $(6,3-15,7)$ & $(12,5-24,7)$ & $(19,2-29,1)$ & $(7,9-13,1)$ & $(14,5-20,3)$ \\
\hline Гиперкинетические & $18,4^{*}$ & $4,2 *$ & 11,4 & 17,4 & 4,6 & 11,2 & $18,1 *$ & $4,3 *$ & 11,4 \\
\hline расстройства & $(14,0-23,7)$ & $(2,5-6,9)$ & $(9,0-14,5)$ & $(9,7-29,3)$ & $(2,0-10,0)$ & $(6,6-18,4)$ & $(13,9-23,1)$ & $(2,8-6,6)$ & $(9,1-14,1)$ \\
\hline
\end{tabular}

Примечание: * мальчики > чем девочки $(\mathrm{p}<0,05)$ 


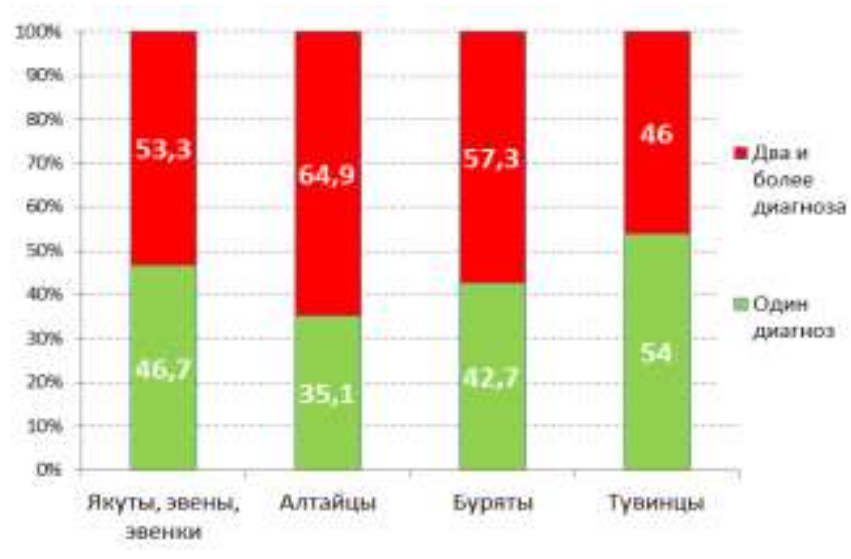

Puc. 2. Частота сочетанных нарушений (\%).

Сочетанные нарушения чаще наблюдались у детей с расстройствами поведения: в $\mathrm{PC}(Я)$ у $53,3 \%$, в РА у $64,9 \%$, в АБО у $57,3 \%$, в РТ у $46 \%$. Наиболее часто встречались сочетания нарушений поведения с гиперкинетическими расстройствами: в $\mathrm{PC}(Я)$ у $42,2 \%$, в РА у $40,4 \%$, в АБО у $38,5 \%$, в РТ у $44 \%$ детей и подростков. Сочетания нарушений поведения с эмоциональными расстройствами отмечались у 6,0\% детей и подростков в $\mathrm{PC}(Я)$, у 10,6\% в $\mathrm{PA}$, у $5,2 \%$ в АБО и у $9 \%$ в РТ. Три и более диагноза поставлены 7,0\% человек в $\mathrm{PC}(Я), 5,3 \%$ в РА, $8,3 \%$ в АБО. В целом, наибольшая коморбидность наблюдалась между расстройствами поведения и гиперкинетическими расстройствами с коэффициентом шансов 57,6 (95\% ДИ = 26,8$54,9) ;(\mathrm{OR}=29,2 ; 95 \% \mathrm{CI}=16,4-51,8)$.

$\mathrm{y}$ детей, имевших эмоциональные расстройства, также часто встречались сочетания двух или более диагнозов: в Якутии - 17,2\%, в РА у $44,7 \%$, в АБО у $38 \%$, в РТ у $49 \%$. При наличии двух диагнозов чаще регистрировались сочетания тревожных расстройств с депрессивными: у $12 \%$ детей в Якутии, у 34,0\% детей на Алтае, у $22 \%$ детей в Агинском Бурятском округе и у $10 \%$ детей в Тыве. У пациентов с депрессивными расстройствами чаще наблюдались множественные нарушения, в основном, сочетания депрессии с тревожными расстройствами и гиперактивностью и /или расстройствами поведения: у $15 \%$ детей в Якутии, $10,6 \%$ на Алтае, у $16 \%$ детей в Агинском Бурятском округе и у $39 \%$ детей в Тыве.

Обсуждение.

Нами была изучена распространённость психических нарушений у детей и подростков коренных популяций Сибири с использованием международно принятых стандартизированных методов и подходов. При сравнении получен- ных показателей у представителей разных коренных народов между собой выявлены территориальные различия в частоте психических нарушений. Самые высокие показатели регистрируются в Республике Тыва (29,2\%), на второе место выходит Республика Саха (16,3\%), на третье место Республика Алтай $(12,1 \%)$, на четвёртое - Агинский Бурятский округ (7,4\%). Частота психических нарушений у детей и подростков в Республики Тыва значительно превышает показатели, полученные у других этносов: у якутов, эвенов и эвенков в 1,8 раз $(16,3 \%$, $\mathrm{p}=0,004)$, у алтайцев в 2,4 раза $(12,1 \%, \mathrm{p}<0,001)$, у агинских бурят в 3,9 раза $(7,4 \%, \mathrm{p}<0,001)$.

При сравнении наших показателей с данными зарубежных авторов, полученных в исследованиях, проведенных с аналогичным дизайном, выявлено, что частота психических нарушений в Якутии, на Алтае и в Агинском Бурятском округе не превышает частоту нарушений в других странах. Так, распространённость психической патологии у детей в скандинавских странах составляет 14,3\% [25], у детей 8-11 лет в Португалии - 16\% [26], у 8-летних мальчиков в Финляндии - 12-18\% [27], у детей в Объединённых Арабских Эмиратах (ОАЭ) $11,8 \%$ [28], у детей 7-15-лет, проживающих в сельской местности Уганды - 18\% [29].

Обращает на себя внимание высокая распространённость психических нарушений у детей и подростков в Тыве, которая превосходит показатели других регионов и стран, за исключением показателей у детей 6-12 лет из Палестины и Сектора Газа (50,5\%), где постоянно ведутся военные действия [30]. Причину высокого уровня психических нарушений в Тыве мы объясняем выраженным социальным неблагополучием, в сравнении с положением в других национальных субъектах РФ [31, 32]. По данным ФСГС, в 2016 году из 85 регионов России Тыва занимала последнее место по среднедушевым доходам населения и предпоследнее по уровню занятости трудоспособного населения. Число зарегистрированных преступлений - разбоев, грабежей, убийств, изнасилований - превышало общероссийские значения от 3 до 9 раз, а показатели смертности от случайных отравлений алкоголем - в 2,3-3,4 раза. В наших более ранних работах по изучению психического здоровья у детей и подростков тувинской национальности показано, что к основным факторам, неблагоприятно влияющим на формирование психического здоровья, 
относятся конфликтные отношения в семье, неполная семья и алкоголизация матери [33, 24]. Выявлена взаимосвязь конфликтов в семье с низким социально-экономическим статусом ( $\mathrm{r}=0,56 ; \mathrm{p}<0,001)$, с наличием родственников с судимостью $(\mathrm{r}=0,38 ; \mathrm{p}<0,001)$ и с алкоголизацией матери $(\mathrm{r}=0,26 ; \mathrm{p}=0,017)$. Показано, что у детей, воспитывающихся в неполных семьях, нарушения поведения и признаки гиперактивности встречаются в два-четыре раза чаще, особенно у мальчиков ( $\mathrm{r}=0,53 ; \mathrm{p}=0,005)$. Показана связь алкоголизации родителей, особенно матери, с нарушениями поведения ( $\mathrm{r}=0,53$; $\mathrm{p}=0,02)$ и эмоциональными расстройствами $(\mathrm{r}=0,54 ; \mathrm{p}=0,02)$ у детей. В большей степени эти факторы влияют на вероятность возникновения психической патологии у мальчиков ( $\mathrm{r}=0,34$; $\mathrm{p}=0,03)$.

По результатам настоящего исследования, у мальчиков всех анализируемых популяций психические нарушения встречаются в 2-3 раза чаще, чем у девочек, что подчеркивает значение мужского пола как основного фактора риска психических расстройств и согласуется с данными зарубежных авторов [34].

В структуре выявленной патологии у детей и подростков коренных популяций Сибири наиболее часто встречаются нарушения поведения, на второе место выходят гиперкинетические расстройства, на третье - эмоциональные. Среди нарушений поведения социализированные расстройства преобладают над несоциализированными более чем в три раза. Среди эмоциональных нарушений тревожные расстройства встречаются в два-три раза чаще, чем депрессивные. Сравнительный анализ структуры психических нарушений показал, что психические расстройства имеют сходную структуру как у представителей разных коренных популяций Сибири, так и у представителей других стран. Так, в структуре психических расстройств у британских детей и подростков [34] социализированные расстройства поведения встречаются в два-четыре раза чаще, чем несоциализированные, а тревожные расстройства - примерно в четыре раза чаще, чем депрессивные.

У детей и подростков коренных народов Сибири обнаружен высокий уровень коморбидности психических нарушений. Наиболее часто встречаются сочетания нарушений поведения с гиперкинетическими расстройствами. У детей, имеющих эмоциональные расстрой- ства, чаще отмечаются сочетания тревожных и депрессивных нарушений. У детей с депрессивными расстройствами чаще наблюдаются множественные нарушения. Высокий уровень коморбидности у представителей коренных популяций, согласуется с результатами эпидемиологических исследований психического здоровья детей и подростков в зарубежных странах, где также были зарегистрированы сочетания нарушений поведения с другими расстройствами, в том числе, с гиперкинетическими, а также сочетания тревожных расстройств с депрессивными [7, 34, 35].

Зарубежными авторами показана неблагоприятная роль сочетанных форм психических нарушений у детей и подростков для формирования суицидального и асоциального поведения, преступности, алкогольной и наркотической зависимости во взрослом возрасте [36]. Наиболее неблагоприятными в прогностическом плане являются сочетания гиперкинетических расстройств с расстройствами поведения, что предсказывает дальнейшее нарушение социальной адаптации, в том числе риск асоциального поведения, преступности и склонности к алкоголизации [37, 38, 39, 40].

В целом, результаты данного исследования подтверждают выводы Раттера и Стивенсона [41] о том, что у представителей разных культур структура и частота психических нарушений обнаруживает больше сходств, чем различий. Роль социально-демографических факторов также является одинаково значимой для различных культур. В частности, мужской пол и низкий социально-экономический статус выступают основными рисками психических нарушений.

В то же время, несмотря на отсутствие выраженных различий в структуре и частоте психических расстройств, обнаруживаются существенные различия в частоте суицида с высокой распространенностью самоубийств среди представителей этнических популяций. Так, в 2016 году уровень суицида в Республике Саха (Якутия) составил 30,2 на 100 тысяч, в Республике Алтай 37,9 на 100 тысяч, в Забайкальском крае 39,9 на 100 тысяч [32], что значительно выше, по сравнению с показателями суицида в Финляндии $(13,8)$, Португалии $(8,6)$, ОАЭ $(2,7)$, Дании $(9,2)$, Норвегии $(10,1)$, Швеции $(11,7)$, Уганды $(20,0)$ [42]. Данные обстоятельства говорят о том, что суицидальное поведение у коренных народов Сибири обусловлено не только 
социально-экономическими и клиническими факторами, но и другими причинами, в том числе этнокультурными.

\section{Выводы:}

1. Распространённость психических расстройств у якутов, эвенов и эвенков составляет $16,3 \%$, у алтайцев $12,1 \%$, у агинских бурят $7,4 \%$, у тувинцев 29,2\%. У мальчиков наруше-

\section{Литература:}

1. Holland K.M., Vivolo-Kantor A.M., Logan J.E., et al. Antecedents of suicide among youth aged 11-15: A multistate mixed methods analysis. Journal of youth and adolescence. 2017; 46 (7): 1598-1610.

2. Cash S.J., Bridge J.A. Epidemiology of Youth Suicide and Suicidal Behavior. Curr. Opin. Pediatr. 2009; 21 (5): 613-619.

3. De Hepcée C., Reynaert C., Jacques D., et al. Suicide in adolescence: attempt to cure a crisis, but also the fatal outcome of certain pathologies. Psychiatr Danub. 2015; 27 (1): 296-299.

4. Luna B., Sweeney J.A. The emergence of collaborative brain function: FMRI studies of the development of response inhibition. Annals of the New York Academy of Sciences. 2004; 1021: 296-309.

5. Delevich K., Thomas A.W., Wilbrecht L. Adolescence and "Late Blooming" Synapses of the Prefrontal Cortex. Cold Spring Harb Symp Quant Biol. 2019; 23. pii: 037507. doi: 10.1101/sqb.2018.83.037507.

6. Windle M., Spear L.P., Fuligni A.J., et al. Transitions into underage and problem drinking: Developmental processes and mechanisms between 10 and 15 years of age. Pediatrics. 2008; 121 (4): 273-289.

7. Angold A., Costello E.J., Erkanli A. Comorbidity. J. Child. Psychol. Psychiatry. 1999; 40: 57-87.

8. Costello E.J., Pine D.S., Hammen C., et al. Development and natural history of mood disorders. Biological Psychiatry. 2002; 52 (6): 529-542.

9. Goldston D.B., Daniel S.S., Reboussin B.A., et al. Psychiatric diagnoses of previous suicide attempters, first-time attempters, and repeat attempters on an adolescent inpatient psychiatry unit. J. Am. Acad. Child Adolesc. Psychiatry. 1998; 37 (9): 924932.

10. Gould M.S., King R., Greenwald S., et al. Psychopathology associated with suicidal ideation and attempts among children and adolescents. J. Am. Acad Child Adolesc. Psychiatry. 1998; 37 (9): 915-923.

11. Reinherz H.Z., Tanner J.L., Berger S.R., et al. Adolescent suicidal ideation as predictive of psychopathology, suicidal behavior, and compromised functioning at age 30. Am. J. Psychiatry. 2006; 163 (7): 1226-1232.

12. Herba C.M., Ferdinand R.F., van der Ende J., et al. Long-term associations of childhood suicide ideation. J. Am. Acad. Child. Adolesc. Psychiatry. 2007; 46 (11): 1473-1481.

13. Kerr D.C. Replicated prediction of men's suicide attempt history from parent reports in late childhood. J. Am. Acad. Child. Adolesc. Psychiatry. 2008; 47 (7): 834-885.

14. O'Keefe V.M., Wingate L.R. The role of hope and optimism in suicide risk for American Indians / Alaska Natives. Suicide Life Threat. Behav.2013; 43 (6): 621-633.

15. Manzo K., Tiesman H., Stewart J., et al. A comparison of risk factors associated with suicide ideation/attempts in American Indian and White youth in Montana. Arch. Suicide Res. 2015; 19 (1): 89-102.

16. Soole R., Kõlves K., De Leo D. Factors related to childhood suicides: analysis of the Queensland Child Death Register. Crisis. 2014; 35 (5): 292-300.

17. Ворсина О.П., Дианова С.В., Белькова Т.Ю. Особенности суицидального поведения детей и подростков в Иркутске. Сибирский вестник психиатрии и наркологии. 2011; 68 (5): 20-24. ния встречаются в 2-3 раза чаще, чем у девочек.

2. Более $40 \%$ детей и подростков с психическими расстройствами имеют сочетанные формы нарушений. Эти дети относятся к группе риска по суицидальному поведению и нуждаются в мерах оперативного медицинского вмешательства.

Reference:

1. Holland K.M., Vivolo-Kantor A.M., Logan J.E., et al. Antecedents of suicide among youth aged 11-15: A multistate mixed methods analysis. Journal of youth and adolescence. 2017; 46 (7): 1598-1610.

2. Cash S.J., Bridge J.A. Epidemiology of Youth Suicide and Suicidal Behavior. Curr. Opin. Pediatr. 2009; 21 (5): 613-619.

3. De Hepcée C., Reynaert C., Jacques D., et al. Suicide in adolescence: attempt to cure a crisis, but also the fatal outcome of certain pathologies. Psychiatr Danub. 2015; 27 (1): 296-299.

4. Luna B., Sweeney J.A. The emergence of collaborative brain function: FMRI studies of the development of response inhibition. Annals of the New York Academy of Sciences. 2004; 1021: 296-309.

5. Delevich K., Thomas A.W., Wilbrecht L. Adolescence and "Late Blooming" Synapses of the Prefrontal Cortex. Cold Spring Harb Symp Quant Biol. 2019; 23. pii: 037507. doi: 10.1101/sqb.2018.83.037507.

6. Windle M., Spear L.P., Fuligni A.J., et al. Transitions into underage and problem drinking: Developmental processes and mechanisms between 10 and 15 years of age. Pediatrics. 2008; 121 (4): 273-289.

7. Angold A., Costello E.J., Erkanli A. Comorbidity. J. Child. Psychol. Psychiatry. 1999; 40: 57-87.

8. Costello E.J., Pine D.S., Hammen C., et al. Development and natural history of mood disorders. Biological Psychiatry. 2002; 52 (6): 529-542.

9. Goldston D.B., Daniel S.S., Reboussin B.A., et al. Psychiatric diagnoses of previous suicide attempters, first-time attempters, and repeat attempters on an adolescent inpatient psychiatry unit. J. Am. Acad. Child Adolesc. Psychiatry. 1998; 37 (9): 924 932.

10. Gould M.S., King R., Greenwald S., et al. Psychopathology associated with suicidal ideation and attempts among children and adolescents. J. Am. Acad Child Adolesc. Psychiatry. 1998; 37 (9): 915-923.

11. Reinherz H.Z., Tanner J.L., Berger S.R., et al. Adolescent suicidal ideation as predictive of psychopathology, suicidal behavior, and compromised functioning at age 30. Am. J. Psychiatry. 2006; 163 (7): 1226-1232.

12. Herba C.M., Ferdinand R.F., van der Ende J., et al. Long-term associations of childhood suicide ideation. J. Am. Acad. Child. Adolesc. Psychiatry. 2007; 46 (11): 1473-1481.

13. Kerr D.C. Replicated prediction of men's suicide attempt history from parent reports in late childhood. J. Am. Acad. Child. Adolesc. Psychiatry. 2008; 47 (7): 834-885.

14. O'Keefe V.M., Wingate L.R. The role of hope and optimism in suicide risk for American Indians / Alaska Natives. Suicide Life Threat. Behav. 2013; 43 (6): 621-633.

15. Manzo K., Tiesman H., Stewart J., et al. A comparison of risk factors associated with suicide ideation/attempts in American Indian and White youth in Montana. Arch. Suicide Res. 2015; 19 (1): 89-102.

16. Soole R., Kõlves K., De Leo D. Factors related to childhood suicides: analysis of the Queensland Child Death Register. Crisis. 2014; 35 (5): 292-300.

17. Vorsina O.P., Dianova S.V., Bel'kova T.Ju. Osobennosti suicidal'nogo povedenija detej i podrostkov v Irkutske [Features of suicidal behavior of children and adolescents in Irkutsk]. Sibirskij vestnik psihiatrii i narkologii. 2011; 68 (5): 20-24. (In Russ) 
18. Ворсина О.П. Клинико-социальные и этнокультуральные особенности суицидального поведения населения Иркутской области: дисс. ... док. мед. наук. Томск, 2012. 359 с.

19. Ворсина О.П. Социально-демографические и клинические характеристики детей и подростков, совершивших завершенные суициды. Сибирский вестник психиатрии и наркологии. 2016; 92 (3): 51-54.

20. Ишимбаева А.Н. Суицидальное поведение у детей и подростков Забайкальского края: автореф. дисс. ... канд. мед. наук. Москва, 2013. 23 с.

21. Злова Т.П., Ишимбаева А.Н., Ахметова В.В. Социальнопсихологические особенности незавершенных суицидов у детей и подростков. (Забайкальский край, г. Чита). Суиџидология. 2011; 2 (2): 27-28.

22. Knyazev G.G., Slobodskaya H.R., Safronova M.V., Kinsht I.A. School adjustment and health in Russian adolescents. Psychol. Health Med. 2002; 7: 143-155.

23. Kumpulainen K., Räsänen E., Burkin M., et al. Comparison of psychiatric symptoms among 8-to 9-year-old children in Finland and Russia. Nord. J. Psychiatry. 1999; 53: 417-26.

24. Slobodskaya H.R., Semenova N.B. Child and adolescent mental health problems in Tyva Republic, Russia, as possible risk for a hire suicide rate. J. Eur. Child Adolesc. Psychiatry. 2016; 25 (4): 361-371.

25. Taanila A., Ebeling H., Kotimaa A., et al. Is a large family a protective factor against behavioural and emotional problems at the age of 8 years? Acta Paediatr. 2004; 93 (4): 508-517.

26. Klein J.M., Gonçalves A., Silva C.F. The Rutter Children Behaviour Questionnaire for teachers: from psychometrics to norms, estimating caseness. Psico-USF. 2009; 14: 157-165.

27. Sourander A., Niemelä S., Santalahti P., et al. Changes in psychiatric problems and service use among 8-year-old children: a 16year population-based time-trend study. J. Am. Acad. Child Adolesc. Psychiatry. 2008; 47: 317-327.

28. Eapen V., Swadi H., Sabri S., et al. Childhood behavioral disturbance in a community sample in Al-Ain, United Arab Emirates. East Mediterr. Health J. 2001; 7 (3): 428-434.

29. Cortina M.A., Sodha A., Fazel M., et al. Prevalence of child mental health problems in Sub-saharan Africa: A systematic review. Arch. Pediatr. Adolesc. Med. 2012; 166: 276-281.

30. Mousa T., Vostanis P. Epidemiology of child health problems in Gaza Strip. East Medditerr. Health J. 2001; 7 (3): 403-412.

31. Регионы России. Социально-экономические показатели. 2017. Росстат. М., 2017. 1402 с.

32. Федеральная служба государственной статистики: http://www.gks.ru

33. Семенова Н.Б., Манчук В.Т. Эмоциональные расстройства и расстройства поведения у детей коренного населения Республики Тыва: распространенность, роль социальных факторов. Сибирский вестник психиатрии и наркологии. 2007; 2 (45): 122-126.

34. Green H., McGinnity A., Meltzer H., Ford T., Goodman R. Mental health of children and young people in Great Britain, 2004. Basingstoke: Palgrave Macmillan. 388 p.

35. Costello E.J., Foley DL, Angold A. 10-year research update review: the epidemiology of child and adolescent psychiatric disorders: II. Developmental epidemiology. J. Am. Acad. Child. Adolesc Psychiatry. 2006; 45: 8-25.

36. Mota V.L. Reformulating attention-deficit/hyperactivity disorder according to signal detection theory. J. Am. Acad. Child. Adolesc. Psychiatry. 2000; 39: 1144-1151.

37. Pickles A., Rowe R., Simonoff E., et al. Child psychiatric symptoms and psychosocial impairment: relationship and prognostic significance. Br. J. Psychiatry. 2001; 179: 230-235.

38. Kumpulainen K. Psychiatric symptoms and in early adolescence predict heavy alcohol use 3 years later. Addiction. 2000; 95: 1847-1857.

39. Kumpulainen K. Symptoms and deviant behavior among eightyear-old as predictors of refferal for psychiatric evaluation by age 12. Psychiatr. Serv. 2002; 53: 201-206.
18. Vorsina O.P. Kliniko-social'nye i jetnokul'tural'nye osobennosti suicidal'nogo povedenija naselenija Irkutskoj oblasti [Clinical, social and ethno-cultural features of suicidal behavior of the population of the Irkutsk region]: diss. ... dok. med. nauk. Tomsk, 2012. 359 s. (In Russ)

19. Vorsina O.P. Social'no-demograficheskie i klinicheskie harakteristiki detej i podrostkov, sovershivshih zavershennye suicidy [Socio-demographic and clinical characteristics of children and adolescents who have committed suicide]. Sibirskij vestnik psihiatrii i narkologii. 2016; 92 (3): 51-54. (In Russ)

20. Ишимбаева А.Н. Суицидальное поведение у детей и подростков Забайкальского края: автореф. дисс. ... канд. мед. наук. Москва, 2013. 23 с. (In Russ)

21. Zlova T.P., Ishimbaeva A.N., Akhmetova V.V. Sociallypsychological features of incomplete suicides at children and teenagers (Transbaikalian edge, Chita). Suicidology. 2011; 2 (2): 27-28. (In Russ)

22. Knyazev G.G., Slobodskaya H.R., Safronova M.V., Kinsht I.A. School adjustment and health in Russian adolescents. Psychol. Health Med. 2002; 7: 143-155.

23. Kumpulainen K., Räsänen E., Burkin M., et al. Comparison of psychiatric symptoms among 8-to 9-year-old children in Finland and Russia. Nord. J. Psychiatry. 1999; 53: 417-26.

24. Slobodskaya H.R., Semenova N.B. Child and adolescent mental health problems in Tyva Republic, Russia, as possible risk for a hire suicide rate. J. Eur. Child Adolesc. Psychiatry. 2016; 25 (4): 361-371.

25. Taanila A., Ebeling H., Kotimaa A., et al. Is a large family a protective factor against behavioural and emotional problems at the age of 8 years? Acta Paediatr. 2004; 93 (4): 508-517.

26. Klein J.M., Gonçalves A., Silva C.F. The Rutter Children Behaviour Questionnaire for teachers: from psychometrics to norms, estimating caseness. Psico-USF. 2009; 14: 157-165.

27. Sourander A., Niemelä S., Santalahti P., et al. Changes in psychiatric problems and service use among 8-year-old children: a 16year population-based time-trend study. J. Am. Acad. Child Adolesc. Psychiatry. 2008; 47: 317-327.

28. Eapen V., Swadi H., Sabri S., et al. Childhood behavioral disturbance in a community sample in Al-Ain, United Arab Emirates. East Mediterr. Health J. 2001; 7 (3): 428-434.

29. Cortina M.A., Sodha A., Fazel M., et al. Prevalence of child mental health problems in Sub-saharan Africa: A systematic review. Arch. Pediatr. Adolesc. Med. 2012; 166: 276-281.

30. Mousa T., Vostanis P. Epidemiology of child health problems in Gaza Strip. East Medditerr. Health J. 2001; 7 (3): 403-412.

31. Regiony Rossii. Social'no-jekonomicheskie pokazateli. 2017. Rosstat [Region of Russia. Socio-economic indicators. 2017 Rosstat]. M., 2017. 1402 c. (In Russ)

32. Federal'naja sluzhba gosudarstvennoj statistiki [Federal state statistics service]: http://www.gks.ru (In Russ)

33. Semenova N.B., Manchuk V.T. Jemocional'nye rasstrojstva i rasstrojstva povedenija u detej korennogo naselenija Respubliki Tyva: rasprostranennost', rol' social'nyh faktorov [Emotional and behavioural disorders in indigenous children of the Republic of Tuva: prevalence, role of social factors]. Sibirskij vestnik psihiatrii i narkologii. 2007; 2 (45): 122-126. (In Russ)

34. Green H., McGinnity A., Meltzer H., Ford T., Goodman R. Mental health of children and young people in Great Britain, 2004. Basingstoke: Palgrave Macmillan. 388 p.

35. Costello E.J., Foley DL, Angold A. 10-year research update review: the epidemiology of child and adolescent psychiatric disorders: II. Developmental epidemiology. J. Am. Acad. Child. Adolesc Psychiatry. 2006; 45: 8-25.

36. Mota V.L. Reformulating attention-deficit/hyperactivity disorder according to signal detection theory. J. Am. Acad. Child. Adolesc. Psychiatry. 2000; 39: 1144-1151.

37. Pickles A., Rowe R., Simonoff E., et al. Child psychiatric symptoms and psychosocial impairment: relationship and prognostic significance. Br. J. Psychiatry. 2001; 179: 230-235.

38. Kumpulainen K. Psychiatric symptoms and in early adolescence predict heavy alcohol use 3 years later. Addiction. 2000; 95: 1847-1857.

39. Kumpulainen K. Symptoms and deviant behavior among eightyear-old as predictors of refferal for psychiatric evaluation by age 12. Psychiatr. Serv. 2002; 53: 201-206. 
40. Rutter M. Commentary: causal process leading to antisocial behavior. Dev. Psychol. 2003; 39: 372-378.

41. Rutter M., Stevenson J. Using epidemiology to plan services: a conceptual approach. In: Rutter M., Bishop D., Pine D., Scott S. Stevenson J., Taylor E., Thapar A. (eds.) Rutter's Child and Adolescent Psychiatry, $5^{\text {th }}$ edn. 2008. Blackwell-Wiley, Oxford, UK, pp. 3-17.

42. Suicide rates, age-standardized. WHO. 2018.
40. Rutter M. Commentary: causal process leading to antisocial behavior. Dev. Psychol. 2003; 39: 372-378.

41. Rutter M., Stevenson J. Using epidemiology to plan services: a conceptual approach. In: Rutter M., Bishop D., Pine D., Scott S. Stevenson J., Taylor E., Thapar A. (eds.) Rutter's Child and Adolescent Psychiatry, $5^{\text {th }}$ edn. 2008. Blackwell-Wiley, Oxford, UK, pp. 3-17.

42. Suicide rates, age-standardized. WHO. 2018.

\section{SUICIDAL BEHAVIOR IN NATIVE CHILDREN AND ADOLESCENTS OF SIBERIA: CLINICAL RISK FACTORS}

\section{N.B. Semenova}

Federal Research Centre "Krasnoyarsk Scientific Centre of Siberian Division of Russian Academy of Sciences", Scientific Research Institute for Medical Problems of the North, Krasnoyarsk, Russia; snb237@gmail.com

\section{Abstract:}

Suicidal mortality indices in native children and adolescents of Siberia are many times higher than average ones for Russian Federation. This demands a thorough analysis of the said social phenomenon to reveal its reasons. Aim of the research. To study the prevalence of psychic disorders in children and adolescents in native populations of Siberia, namely in the Yakuts, the Evens, the Evenks, the Altayans, the Aginsk Buryats and the Tyvins using internationally-recognized standard methods. Subjects and Methods of the Research. The authors examined children and adolescents in the ages from 7 to 15 years, schoolchildren of common schools, rural inhabitants of four national districts of RF: Sakha Republic (Yakutia), Altay Republic, Aginsk Buryatskiy District and Tyva Republic. There were two stages of the examination. On the first stage we performed screening for psychic health in 5208 children and adolescents (1662 Yakuts, Evens and Evenks, 1044 Altayans, 1797 Buryats, 705 Tyvins) implementing M.Ratter questionnaire for teachers (RTQ, B scale). The second stage included more detailed psychic evaluation for the children with RTQ scale negative results. Results. Prevalence of psychic disorders among the Yakuts, the Evens and the Evenks amounted at $16.3 \%$, the Altayans $12.1 \%$, the Aginsk Buryats $7.4 \%$, the Tyvins $29.2 \%$. In boys the disturbances have been marked 2-3 times more often than in girls. In the structure of psychic disorders, behavior disorders ranked first, second place belonged to hyperkinetic disorders and the third - emotional disorders. More than $40 \%$ of children and adolescents with psychic disorders showed combinatory forms. Conclusions. The results refer to the necessity to work out the measures of medical intervention aimed at effective assistance to the children and adolescents with the problems of psychic health.

Keywords: adolescents, children, suicide, native people, Siberia, risk factors, psychic health, epidemiology

Благодарности. Автор выражает огромную благодарность за помощь в организации экспедиционных исследований директору РЦ ПМСС Республики Саха (Якутия) (РС (Я)), заслуженному работнику образования РС (Я) В.Н. Филиппову и его заместителю по учебно-методической работе, почетному работнику образования РФ, отличнику образования РС (Я) Т.Ф. Мартыновой; работникам администрации Агинского Бурятского округа Забайкальского края в лице консультанта отдела соц. развития С.Б. Базарова и зам. начальника отдела соц. развития Р.М. Балдоржиевой; начальнику отдела образовательной политики Министерства образования и науки Республики Алтай О.С. Саврасовой.

Автор благодарит за помощь в проведении исследований работников образования и здравоохранения РС (Я): зав. отделом инновационных технологий РЦ ПМСС Мин. Обр. РС(Я) Р.Н. Андрееву; зав. РПМПК РЦ ПМСС Мин. Обр. РС (Я) И.И. Андрееву; педагогов-психологов РЦ ПМСС Мин. Обр. РС (Я) Е.Н. Семенову, А.Ф. Петрову и А.Н. Андросову; специалиста управления образованием Олекминского района Н.С. Макарову; врача психиатра ГУ ЯРПНД МЗ РС (Я) Е.В. Мордосову; врача педиатра ЦБ Усть-Майского улуса Ю.Е. Ноеву; врачей психиатров РПМПК РЦ ПМСС Мин. Обр. РС (Я) Т.Н. Саввину и Т.С. Сивцеву.

Автор благодарен за помощь в сборе и обработке полученного материала научным сотрудникам ФИЦ КНЦ СО РАН, г. Красноярска: в.н.с., к.м.н. В.А. Вшивкову, в.н.с., к.м.н. А.Ю. Холомеевой; в.н.с., к.м.н. Л.В. Лаптевой; н.с. Н.Г. Муравьевой; медицинским психологам КГБУЗ ККПНД №1 А.Ф. Музафаровой, Е.Е. Долгушиной, Ю.Н. Орловой.

Финансирование: Исследование выполнено при финансовой поддержке грантов РГНФ № 12-06-18006 "Социальные и этнопсихомогические предпосылки суицидального поведения у подростков Бурятии"; гранта РГНФ № 13-06-18001 "Социальные и этнопсихологические предпосылки формирования суицидального поведения у подростков Республики ААтай»; контракта НИР №12-01/06 от 12.07.2013 г. "Закономерности формирования психического здоровья коренных и малочисленных народов Республики Саха (Якутия)".

Конфликт интересов: Автор декларирует отсутствие явных и потенциальных конфмиктов интересов, о которых необходимо сообщить в связи с публикацией данной статьи.

Для цитирования: Семёнова Н.Б. Суицидальное поведение у детей и подростков коренных народов Сибири: клинические факторы риска. Суицидология. 2019; 10 (1): 36-47. doi.org/10.32878/suiciderus.19-10-01(34)-36-47

For citation: $\quad$ Semenova N.B. Suicidal behavior in native children and adolescents of Siberia: clinical risk factors. Suicidology. 2019; 10 (1): 36-47. (In Russ) doi.org/10.32878/suiciderus.18-10-01(34)-36-47 